\title{
Water and electrolyte absorption by the colon in tropical sprue
}

\author{
B S RAMAKRISHNA and V I MATHAN* \\ From the Wellcome Research Unit, Christian Medical College Hospital, Vellore, India
}

SUMMARY A defect in colonic absorption of electrolytes and water was demonstrated in patients with tropical sprue by perfusing the colon with normal saline containing a non-absorbable marker. Colonic water absorption correlated negatively with stool weight and was abnormal in patients with steatorrhoea. The possible mechanisms producing this defect are discussed. This defect may be related to colonocyte damage produced by unabsorbed unsaturated fatty acids in patients with steatorrhoea.

Damaged small intestinal enterocytes cause malabsorption of nutrients in tropical sprue. ${ }^{1}$ The pathogenesis of diarrhoea with increased stool weight, however, the commonest clinical feature in tropical sprue, is not yet fully understood. ${ }^{2}$ A defect in small intestinal water and electrolyte absorption $^{3-5}$ sufficient to cause diarrhoea could not be confirmed in southern Indian patients with tropical sprue. $^{6}$ Fluid and electrolyte malabsorption in the small intestine was not severe enough to explain the degree of diarrhoea, in view of the colonic reserve capacity to absorb sodium and water. ${ }^{7}$ It therefore appeared reasonable to investigate the absorption of electrolytes and water by the colon in a group of southern Indian patients with tropical sprue and appropriate controls using total colonic perfusion with normal saline containing a non-absorbable marker.

\section{Methods}

All patients and controls were admitted to a metabolic ward and detailed studies of small intestinal structure and function were carried out as described elsewhere. ${ }^{2}$ Informed consent was obtained from all subjects and the protocol was approved by the research committee of this institution. Ten consecutive patients admitted with a diagnosis of tropical sprue of more than three months' duration ${ }^{89}$ were studied. Ten age- and

\footnotetext{
* Address for correspondence and reprints: Professor V I Mathan, Wellcome Research Unit, CMC Hospital, Vellore 632004, India.

The Wellcome Research Unit is supported by The Wellcome Trust, London. Received for publication 17 February 1982
}

sex-matched healthy asymptomatic volunteers from villages kept under surveillance by the Unit were also studied as controls.

The entire colon was perfused at a constant rate through one of three polyvinyl radiopaque tubes (internal diameter $1.5 \mathrm{~mm}$ ) cemented together; the distal opening positioned fluoroscopically in the caecum after oral passage had a mercury balloon attached to it and was used for perfusion with normal saline with $4 \mathrm{~g} / \mathrm{l}$ of polyethyleneglycol (PEG molecular weight nominally 4000 ) as the nonabsorbable marker. ${ }^{11}{ }^{11}$ Two other openings, $20 \mathrm{~cm}$ and $60 \mathrm{~cm}$ orad from the distal opening, were used to monitor the volume and recovery of ileal contents with phenolsulphonphthalein (PSP) injected through the most proximal opening at one hour intervals throughout the study period with continuous suction applied to the opening $40 \mathrm{~cm}$ further down. The position of the tip of the tube in the caecum was confirmed fluoroscopically at the beginning of the perfusion, at two hourly intervals throughout the studies and at the end of perfusion. The rate of perfusion, $5 \mathrm{ml}, 10 \mathrm{ml}$, and $15 \mathrm{ml}$ per minute, was controlled by a constant infusion pump (Watson Marlow, UK) and the order of perfusion was randomised in each subject. The effluent from the colon was collected through a $30 \mathrm{~F}$ soft rubber catheter positioned at the dentate line.

During the passage of the tube the subjects were allowed their normal diet. When the tube reached the caecum the subject was fasted for eight hours and then the colon washed out with 1 to 21 normal saline till the return was free of faeces and mucus. The patient was encouraged to empty the colon and 
about an hour after this perfusion was started. At the beginning of perfusion two hours were given for achieving steady state and between each change of perfusion rate one hour. ${ }^{10}$ After achieving steady state, four 15 minute samples were collected through the rectal tube for analysis. Calculations of net water and electrolyte movements were done according to standard formulae. ${ }^{11}$ Concentrations of sodium and potassium were determined by flame photometry, chloride by titration against murcuric nitrate, and PEG by turbidimitry. ${ }^{12}$ PSP was measured spectrophotometrically at $560 \mu \mathrm{m}$ after precipitation of bile pigments. ${ }^{13}$ In seven subjects in each group the residual volume in the colon was determined by quantifying the volume infused and recovered.

\section{Results}

The mean net water, sodium, and chloride absorption by the colon in patients with tropical sprue was significantly lower compared with the controls at each rate of perfusion (Table 1). Net secretion of potassium into the perfusate was also higher in patients with sprue, although the difference was significant only at the $10 \mathrm{ml} / \mathrm{min}$ rate of perfusion (Table 1). Net secretion of water into the lumen was found in several of the patients with tropical sprue (Fig. 1), but net secretion of sodium was seen in only one patient (Fig. 2).

Table 1 Net movement of water, sodium, chloride, and potassium in 10 patients with tropical sprue and 10 normal controls

\begin{tabular}{|c|c|c|c|}
\hline & \multicolumn{3}{|c|}{ Perfusion rate $(\mathrm{ml} / \mathrm{min})$} \\
\hline & 5 & 10 & 15 \\
\hline \multicolumn{4}{|c|}{ Water absorption (ml/min) } \\
\hline $\begin{array}{l}\text { Normal } \\
\text { sprue } \\
\text { p }\end{array}$ & $\begin{array}{l}1.38(0.79) \\
0 \cdot 14(0.55) \\
0.01\end{array}$ & $\begin{array}{l}2 \cdot 02(1 \cdot 22) \\
0 \cdot 10(1 \cdot 15) \\
0.01\end{array}$ & $\begin{array}{l}2.42(1.97) \\
0.50(1.12) \\
0.05\end{array}$ \\
\hline \multicolumn{4}{|c|}{ Sodium absorption $(\mu \mathrm{mol} / \mathrm{min})$} \\
\hline $\begin{array}{l}\text { Normal } \\
\text { sprue } \\
\mathrm{p}\end{array}$ & $\begin{array}{l}350(132) \\
117(107) \\
0 \cdot 01\end{array}$ & $\begin{array}{l}530(243) \\
146(190) \\
0.001\end{array}$ & $\begin{array}{l}774(507) \\
250(104) \\
0.01\end{array}$ \\
\hline \multicolumn{4}{|c|}{ Chloride absorption ( $\mu \mathrm{mol} / \mathrm{min})$} \\
\hline $\begin{array}{l}\text { Normal } \\
\text { sprue } \\
\mathrm{p}\end{array}$ & $\begin{array}{l}474(121) \\
234(94) \\
0 \cdot 001\end{array}$ & $\begin{array}{l}846(259) \\
396(172) \\
0 \cdot 01\end{array}$ & $\begin{array}{l}1134(541) \\
561(153) \\
0 \cdot 01\end{array}$ \\
\hline \multicolumn{4}{|c|}{ Potassium secretion $(\mu \mathrm{mol} / \mathrm{min})$} \\
\hline $\begin{array}{l}\text { Normal } \\
\text { sprue } \\
\mathrm{p}\end{array}$ & $\begin{array}{l}13 \cdot 1(12 \cdot 6) \\
23 \cdot 2(6 \cdot 9) \\
\text { NS }\end{array}$ & $\begin{array}{l}20(8 \cdot 3) \\
32 \cdot 1(14 \cdot 6) \\
0 \cdot 05\end{array}$ & $\begin{array}{l}26 \cdot 2(16 \cdot 1) \\
44 \cdot 9(29) \\
\text { NS }\end{array}$ \\
\hline
\end{tabular}

Numbers indicate mean values, while numbers in parentheses represent the standard deviation.

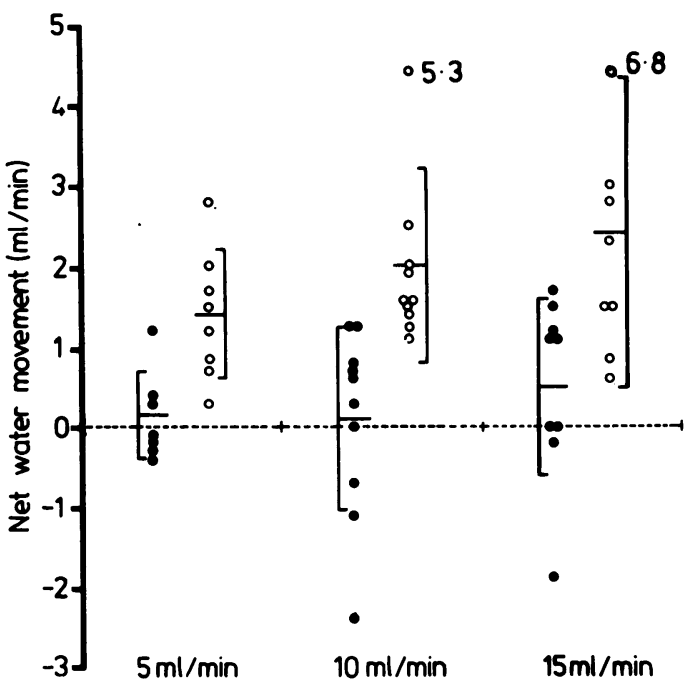

Fig. 1 Net water movement in patients with tropical sprue $(\bullet)$ and controls (०), at different rates of perfusion. Several of the patients had net water secretion.

There was an inverse correlation $(p<0.05)$ between water absorption and stool weight (Fig. 3). This correlation was best using data obtained with $10 \mathrm{ml}$ per minute perfusion. The best discrimination between controls and patients with tropical sprue was also seen at the $10 \mathrm{ml} / \mathrm{min}$ perfusion (Table 1).

All patients with tropical sprue had steatorrhoea, while all controls had normal faecal fat. Mean PSP recovery in patients was $40 \%$ with $37 \mathrm{ml}$ of fluid recovered from the terminal ileum and in controls $29 \%$ with $37.5 \mathrm{ml}$ of fluid recovered. The mean residual volume of fluid in the colon at the end of perfusion at each rate suggested that there was some

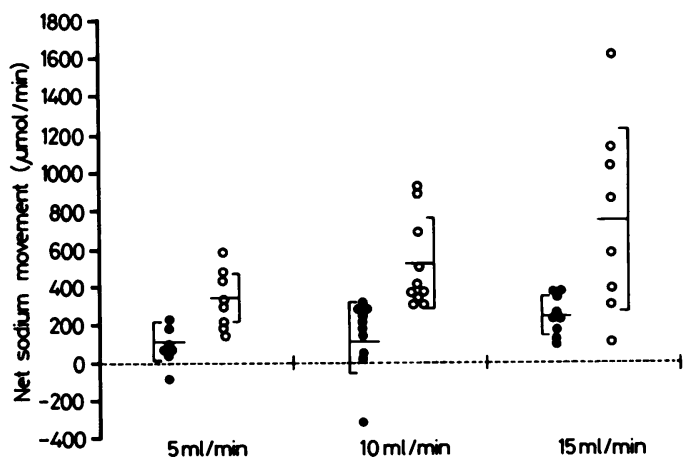

Fig. 2 Net sodium movement in patients with tropical sprue $(\bullet)$ and controls $(\circ)$, at different rates of perfusion. 


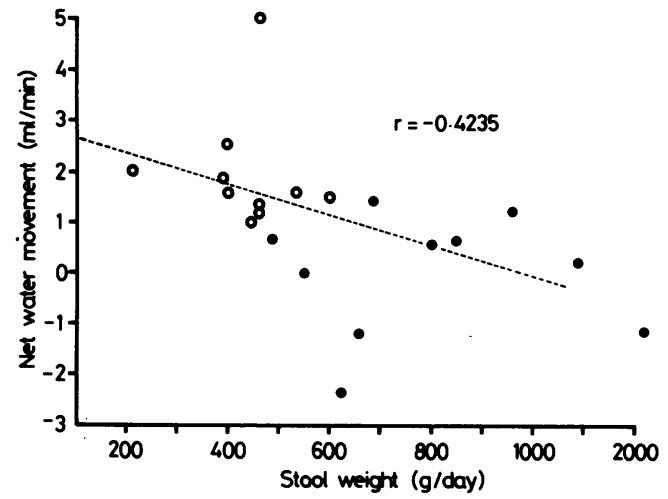

Fig. 3 Correlation between colonic net water movement and faecal weight (sprue $\bullet$, controls $\circ$ ).

Table 2 Mean residual volume of fluid in colon at different rates of perfusion in 10 control subjects and 10 patients with sprue

\begin{tabular}{llll}
\hline & \multicolumn{3}{l}{ Perfusion rate $($ ml $/$ min) } \\
\cline { 2 - 4 } & 5 & 10 & 15 \\
\hline Normal $(\mathrm{ml})$ & 885 & 994 & 983 \\
SD & 90 & 90 & 150 \\
Tropical sprue $(\mathrm{ml})$ & 826 & 860 & 898 \\
SD & 135 & 160 & 130 \\
\hline
\end{tabular}

distension of the colon with the higher rates of perfusion (Table 2). The colon of patients with tropical sprue retained less fluid, although the differences were not statistically significant.

\section{Discussion}

Patients with tropical sprue absorb significantly less electrolytes and water from the colon than comparable controls under identical experimental conditions. The method used in the present study is similar to earlier reports investigating the capacity of the colon to absorb water and electrolytes. ${ }^{10} 11$ 14-16 The amount of water and electrolytes absorbed by the colon increased with increasing rates of perfusion, although the percentage of the infusate absorbed decreased, as has been noted by other workers. ${ }^{7}$ The slowest rate of perfusion used in this study, $5 \mathrm{ml} / \mathrm{min}$, is higher than the normal rate of efflux from the ileum to the colon. ${ }^{7}$ Patients and matched controls were studied under identical conditions, however, and comparison between the two groups is therefore valid. The volume of ileal flow as measured by PSP recovery was small; the rate of recovery of the marker was higher in the patient group. The reduction in colonic absorption is therefore unlikely to be due to a disproportionately high ileal efflux in patients with tropical sprue. The rates of perfusion used here are probably in the upper range of fluid flow through the colon in conditions such as cholera, ${ }^{17}$ where the volume of ileal effluent has been shown to overcome the absorptive capacity of the colon. It is probably better to test the colonic capacity under conditions which are above the physiological capacity to absorb to bring out the differences between controls and groups of patients under conditions of stress.

The mean absorption of water, sodium, and chloride in patients with sprue was significantly lower than that in controls at each rate of perfusion. In addition, several of the patients had net water secretion, which was not found in the controls. These results support the hypothesis that, in southern Indian patients with tropical sprue, there is a functional defect in the colon leading to colonic water and electrolyte malabsorption. The significant inverse correlation between faecal weight and the amount of water absorbed at $10 \mathrm{ml} / \mathrm{min}$ (Fig. 3) suggests that this defect may be contributing significantly to diarrhoea in tropical sprue.

Several possible mechanisms could contribute to the pathogenesis of this colonic lesion in tropical sprue. Electronmicroscopic examination of colonic biopsies is necessary to see if the agent that damages enterocytes $^{1}$ also damages colonocytes. Enterotoxin production by bacteria resident in the colon could produce net water and electrolyte secretion as seen in the small bowel in cholera. An osmotic effect caused by unabsorbed nutrients, especially carbohydrates, is unlikely to be a cause, as under the conditions of the experiments the colon is washed clean and only iso-osmotic solutions are perfused. Malabsorption of bile acids with increased faecal loss does occur in some patients with sprue ${ }^{18}$ and bile acids have been shown to produce colonic water malabsorption under experimental conditions. ${ }^{19} 20$ Another possible mechanism is the effect of free fatty acids on the colonocyte. In the present study all the patients had steatorrhoea. Free fatty acids are increased in faeces of patients with tropical sprue, although hydroxy fatty acids are not present in significant amounts. ${ }^{21}$ Free unsaturated fatty acids inhibit sodium, potassium activated adenosine triphosphatase, and magnesium activated adenosine triphosphatase of the basolateral membrane of colonocytes. The constant exposure of colonocytes to fatty acids present in colonic contents could well be a factor in the pathogenesis of the observed changes in colonic function. 


\section{References}

1 Mathan M, Mathan VI, Baker SJ. An electronmicroscopic study of jejunal mucosal morphology in control subjects and in patients with tropical sprue. Gastroenterology 1975; 68: 17-32.

2 Baker SJ, Mathan VI. Tropical sprue in southern India. In: Tropical sprue and megaloblastic anaemia. A Wellcome Trust Collaborative Study. London: Churchill Livingstone, 1971: 189-261.

3 Fordtran JS, Rector FC. Locklear TW, Ewton MF. Water and solute movement in the small intestine of patients with sprue. J Clin Invest 1967; 46: 287-98.

4 Banwell JG, Gorbach SL, Mitra R et al. Tropical sprue and malnutrition in West Bengal. II. Fluid and electrolyte transport in the small intestine. Am J Clin Nutr 1970; 23: $1559-68$.

5 Corcino JJ, Maldonado M, Klipstein FA. Intestinal perfusion studies in tropical sprue. I. Transport of water, electrolytes and d-xylose. Gastroenterology 1973; 65: 192-9.

6 Hellier MD, Bhat P, Albert J, Baker SJ. Intestinal perfusion studies in tropical sprue. 2. Movement of water and electrolytes. Gut 1977; 18: 480-3.

7 Debongnie JC, Phillips SF. Capacity of the human colon to absorb fluid. Gastroenterology 1978; 74: 698-703.

8 Baker SJ, Mathan VI. Natural history of tropical sprue in south India. Proceedings of Tropical Medicine Conference. London: Pitman, 1968: 65-85.

9 Klipstein FA, Baker SJ. Regarding the definition of tropical sprue. Gastroenterology 1970; 58: 717-9.

10 Devroede GJ, Phillips SF. Studies of the perfusion technique for colonic absorption. Gastroenterology
1969; 56: 92-100.

11 Levitan R, Fordtran JS, Burrows BA, Ingelfinger FJ. Water and salt absorption in the human colon. J. Clin Invest 1962; 41: 1754-9.

12 Hyden S. A turbidimetric method for determination of higher polyethylene glycols in biological materials. Ann Roy Agr Coll (Sweden) 1956; 22: 139-45.

13 Hollander F, Penner A. Secretory studies in whole stomachs: the determination of phenol red in gastric contents. Am J Dig Dis 1940; 7: 199-202.

14 Levitan R, Ingelfinger FJ. Effect of d-aldosterone on salt and water absorption from the intact human colon. $J$ Clin Invest 1965; 44: 801-8.

15 Devroede GJ. Soffie M. Colonic absorption in idiopathic constipation. Gastroenterology 1973; 64: 552-61.

16 Rask-Madsen J. Simultaneous measurement of electrical polarisation and electrolyte transport by the entire normal and inflamed human colon during in vivo perfusion. Scand J Gastroenterol 1973; 8: 327-36.

17 Banwell JC, Pierce NF, Mitra RC et al. Intestinal fluid and electrolyte transport in human cholera. J Clin Invest 1970; 49: 183-95.

18 Kapadia CR, Baker SJ. The increased rate of loss, and non-exponential excretion of bile salts in patients with tropical sprue and ilectomy. Aust NZ J Med 1973; 3: 260-3.

19 Mekhjian HS, Phillips SF, Hoffmann AF. Colonic secretion of water and electrolytes induced by bile acids: perfusion studies in man. J Clin Invest 1971; 50: 1569-77.

20 Binder HJ, Rawlins CL. Effect of conjugated dihydroxy bile salts on electrolyte transport in rat colon. J Clin Invest 1973; 52: 1460-66.

21 Tiruppathi C, Hill PG, Mathan VI. Faecal fatty acids in tropical sprue. Gut. (In press.) 